\title{
The Krantz collections of palaeontology held at the University of Coimbra (Portugal): a century of teaching and museum activities
}

\author{
Pedro M. Callapez ${ }^{\mathrm{a}, \mathrm{b}}$, José M. Brandão ${ }^{\mathrm{c}}$, Ricardo Paredes ${ }^{\mathrm{d}, \mathrm{e}}$, Fernando Barroso-Barcenilla ${ }^{\mathrm{d}, \mathrm{f}}$, Vanda F. Santos ${ }^{\mathrm{b}, \mathrm{g}}$ \\ and Manuel Segura ${ }^{\mathrm{f}}$ \\ ${ }^{a}$ Departamento de Ciências da Terra, Universidade de Coimbra, 3000-272 Coimbra, Portugal; ${ }^{b}$ Centro de Geofísica da Universidade de \\ Coimbra (FCT), Coimbra, Portugal; ${ }^{c}$ Centro de Estudos de História e Filosofia da Ciência, Universidade de Évora, Évora, Portugal; \\ ${ }^{d}$ Departamento de Paleontología, Universidad Complutense de Madrid, 28040 Madrid, Spain; ${ }^{e}$ IMAR-CMA, Universidade de Coimbra, \\ Coimbra, Portugal; ${ }^{f}$ Grupo de Investigación IBERCRETA, Universidad de Alcalá de Henares, 28871 Alcalá de Henares, Spain; ${ }^{g}$ Museu \\ Nacional de História Natural e da Ciência, 1250-102 Lisboa, Portugal
}

(Received 6 February 2014; accepted 25 June 2014)

\begin{abstract}
The University of Coimbra holds a large repository of palaeontological collections bought from European mineral dealers, during the late nineteenth and early twentieth centuries. Among these specimens currently available at the Science Museum stand out three collections acquired from the Krantz house, between 1890 and 1913, for the Section of Mineralogy and Geology of the Natural History Museum. Their taxonomic diversity is high, as well as their geographic and stratigraphic wide-range origins, representing many classical locations and sedimentary formations of the European geology, and overseas countries. These collections have been used since long for teaching in practical classes of Natural Sciences at the University, using hands-on procedures. Together with other contemporary Krantz collections, known by several Iberian institutions, reveal an important heritage with both scientific and historical relevance that should be preserved, studied and reviewed from a scientific point of view.
\end{abstract}

Keywords: palaeontology; historical collections; Krantz; University of Coimbra; Iberian institutions

\section{Introduction}

It is common sense to assume that the teaching of Natural Sciences cannot be dissociated of practical training, that is, handling samples, specimens or models in classroom or laboratory environments. This reality presupposes that the repeated use of object-based learning procedures is highly effective as a complement of expositive theoretical contents, especially if based on 'good quality' collections, well organised and carefully prepared by the professor (Cain 2005). The direct engagement with objects, including those from Natural History collections, is a significant method to develop transferable skills like observation and deduction abilities, capacity of critical analysis and group share (Sparks 2010). It is also one of the best ways for a longer didactic recall, even if compared with modern techniques evolving digital analogies with object images (Simpson and Hammond 2012).

These teaching and learning 'old' strategies can be traced back to the Renaissance or even before that, but they are commonly associated with the philosophic ideas and ideals of the Enlightenment, when geology and life sciences emerged from closed and elitist circles to be available to large groups of citizens (Huxley 2007). This diffusion of knowledge, at least for the emerging middle class and bourgeoisie of that time, was the seed from which a new generation of scientists and engineers was born, and destined to lead the frontline of Industrial Revolution and its socioeconomic and political changes (Hobsbawm 1975; Hall 1976).

Collectables and collections are as old as civilisation itself, and the early collectors of natural objects date back to the Greco-Roman antiquity (Lewis 2004). This relationship between the discovery of Nature and the Human propensity to inquire helps to justify the profusion of Cabinets of Curiosities, Natural History Museums and private collections throughout the last centuries, including several in Portugal and Spain (Antunes 1986, 1992, 2000; Gruzman and Siqueira 2007; Brandão 2009a). It also explains why recent and old museum collections are so important for scientific, educational and outreach purposes, needing a continuous and professional care, and a conscientious procedure by the staff of each institution, following international guidelines or standards (Brandão and Restrepo 2006).

The Natural History collections are a mirror of the natural world and the single way for many people to observe alive or preserved natural beings, minerals, rocks and fossils away from their original environments. This capacity of being repositories from remote and inaccessible sites on Earth is one of the several reasons that can explain why old cabinets and museums from European institutions of education are so rich and diverse in

*Corresponding author. Email: callapez@dct.uc.pt

(C) 2014 Taylor \& Francis 